\title{
Stress as a Risk Factor for Cardiovascular Events
}

\section{Mercanoglu $\mathbf{G}^{1^{*}}$, Macit $\mathbf{C}^{2}$ and Mercanoglu $\mathrm{F}^{3}$}

${ }^{1}$ Biruni University, Faculty of Pharmacy, Department of Pharmacology, Istanbul-Turkey

${ }^{2}$ Yeditepe University, Faculty of Pharmacy, Department of Clinical Pharmacy and Pharmacology, Istanbul-Turkey

${ }^{3}$ Istanbul University, Istanbul Medical Faculty, Department of Cardiology, Istanbul-Turkey

\section{Introduction}

Almost eight decades passed after the first definition of the term "stress". In 1936 Hans Selye defined this term as "the nonspecific response of the body to any demand for change" which was later referred to as "general adaptation syndrome". Simply put, this model suggests that all stimuli are "stressors" which produce general response regardless of the stressors, and this result in disruption in the balance and homeostasis of the organism [1]. Today, however, we know that stress response varies according to the individual, being acute or chronic in nature, duration and whether it's avoidable or not. According to Dr. Selye "general adaptation syndrome" has three phases: 1) activation (Fight or Flight response for challenging the stressor) 2) adaptation (chronic adaptation to the stimulus), and 3) failure [2]. Failure to "cope adequately" with stressors results in "diseases of adaptation" like hypertension, gastric and/or duodenal ulcers and various mental disorders. Today, we know that stress response is an adaptive mechanism in a short term, but if it continues for a longer term at a certain level, it becomes maladaptive.

Selye's definition of stress gave way to studies that aimed at the evaluation of biological stress and its effects. Until today, thousands of studies have been conducted and still many researchers continue to make advances by connecting stress to illnesses and discovering the mechanisms underlying this connection in order to help for developing effective therapies in clinical practices.

Many in-vitro and in-vivo studies have shown the role of biological stress (such as oxidative and hemodynamic stress) in the development of cardiovascular disease (CVD) and biological risk factors (such as hypertension, dyslipidemia and diabetes) inducing biological stress $[3,4]$. Still, recent studies showed that a high number of cardiovascular events occur in people with one or no risk factor at all $[5,6$. Therefore, besides these traditional risk factors, other risk factors should be considered.

In addition to biological stress, other types of stress such as mental and emotional stress are related to CVD. Nowadays, Dr Selye's hypothesis, "rising up systemic stress via excessive mental stress and representation of its symptoms in peripheral tissues" is now well accepted [7]. It is also well known that mental and/or emotional stress lead to psychological modulations, such as depression, anxiety, panic disorder, which are also closely associated with the pathogenesis of CVD. Today, depression is accepted as stronger risk factor for myocardial infarction (MI) than other traditional risk factors [8]. Therefore, better understanding of the role of mental and/or emotional stress in the pathogenesis of CVD together with the associated stress response mechanisms will help us develop effective treatment strategies in daily clinical practice.

\section{Social and Psychological Factors that Trigger Cardiovascular Diseases}

Stress factors that trigger cardiovascular events can be classified into three categories: emotional stress, mental stress and biological stress. There is profound evidence showing the relationship between biological stressors, such as oxidative stress and/or hemodynamic stress, and cardiovascular events. However, these are not considered within the scope of this review.

It is well known that mental and/or emotional stress lead to psychological modulations such as depression, anxiety, panic disorder that are also closely associated with the pathogenesis of CVD. According to the many clinical and epidemiological studies a wide range of social and psychological factors have been correlated with the pathogenesis of CVD. Available evidences can be categorized in four main aspects [9]: 1) Social factors 2 ) chronic stress 3 ) emotional disorders 4) personality traits

\section{Social factors}

Common social factors are insufficient psychosocial help and low socioeconomic statue. There are two components of psychosocial help. The first is the social network that explains the frequency, type and magnitude of the communication and the second one is the social support provided from this social network. This support can be financial, informational (providing of required info) and emotional (feel of somebody to be loved by another person). Many studies report that the frequency of cardiac deaths increases in the case of insufficient support from social network [1]. In these studies, low psychosocial help has been associated with the situation of not being able to communicate with social network, because of living lonely [10] or as a result of social isolation $[11,12]$ due to lack of self-confidence. Socio-economical statue can be defined as individual's income level, educational level and social statue. Many epidemiological researches showed that socioeconomical statue is a factor, which determines the prognosis of many pathological events whether they are cardiovascular-originated, or not [13].

\section{Chronic stress}

Although chronic stress can be related to both work and family factors, work stress is the more investigated factor. There are many epidemiological researches showing that work stress is responsible from important unwanted cardiovascular effects in sub clinic atherosclerosis and cardiac arrhythmia-related sudden deaths [14-16]. However according to the Multiple Risk Factor Interventional Trial (MRFIT), which was conducted in males with known heart disease, compared to work related stress, family related stress was associated with the

*Corresponding author: Guldem Mercanoglu, Dr. Biruni University, Faculty of Pharmacy, Department of Pharmacology, Istanbul-Turkey, Tel: 00905362673880; E-mail: guldemiko@gmail.com

Received: March 28, 2015; Accepted: May 12, 2015; Published: May 17, 2015

Citation: Mercanoglu G, Macit C, Mercanoglu F (2015) Stress as a Risk Factor for Cardiovascular Events. Cardiol Pharmacol 4: 140. doi:10.4172/2329-6607.1000140

Copyright: (C) 2015 Mercanoglu G et al. This is an open-access article distributed under the terms of the Creative Commons Attribution License, which permits unrestricted use, distribution, and reproduction in any medium, provided the original author and source are credited. 
increased risk of cardiovascular events [17]. Similar results were also given in female population [18].

\section{Emotional disorders}

There are numerous trials demonstrating a significant correlation between depression and increased cardiovascular risk. For example, the INTERHEART study aimed to evaluate the relationship between psychosocial factors and the incidence of MI in 11.119 patients with a history of acute myocardial infarction (AMI) and 13.648 healthy control subjects. The odds ratio for depression was 1.38 (99\% CI 1.191.61), adjusted for age, gender, geographic region and the smoking status [19]. Subsequent epidemiological studies have also showed a correlation between major depressive episodes and increased incidence of cardiovascular events both in a population of healthy subjects and in people with known cardiovascular disease [20-24]. However, growing bodies of studies have failed to detect this relation in patients with ischemic heart disease [25-28]. The conflicting results can be due to the usage of different depression scales for classifying participants as depressed.

On one hand, depression is a risk factor for CVD when it is observed in healthy person; on the other hand, it is an aggravating factor for prognosis of the related cardiac disease when it is shown in the base of a cardiovascular illness. Depression developed at the base of a CVD both increases the sudden cardiac deaths and causes worse prognosis of the cardiac disorder. This situation is usually observed in major depression, yet, though less in frequency, it is seen in moderate depressive conditions as well. According to the results of a meta-analysis, post-MI depression is associated with a 2- to 2.5 -fold increased risk of a poor cardiovascular outcome [29].

At this point, we have to mention that there is a bidirectional relation between depression and CVD. Depression is considered to be a risk factor and at the same time it is a result of cardiovascular disorders. The incidence of depression after an AMI is 65\% (15-25\% of are major depression) [30]. As to the result of another study, depression incidence in patients after AMI, during the treatment process in hospital or in the first year, is $31,5 \%$ [31]. In the same study, it is reported that the depression appears in these patients is chronic and it begins in two weeks after AMI and continues for three months. From these results it can be concluded that the relationship between depression and CVD create a vicious cycle.

Despite this close relationship between depression and cardiovascular events, the results of two large clinical trials are disappointing. According to the Sertraline Antidepressant Heart Attack Randomized Trial (SADHART) [32] and Enhancing Recovery in Coronary Heart Disease Patients Randomized Trial (ENRICHD) [33]; sertraline (a serotonin reuptake inhibitor) and cognitive behavioral therapy were effective in treating symptoms of depression, but ineffective in decreasing major end point such as mortality and morbidity.

Similar to depression, an association between anxiety disorders and cardiovascular events was demonstrated both in healthy subjects $[34,35]$ and people with known heart disease $[28,29$. However, in these studies the methodological differences in assessing anxiety makes the comparison of the results difficult [7].

\section{Personality traits}

Epidemiological studies showed significant increase in cardiovascular events in healthy subjects and a worse prognosis in people with known heart disease characterized with type A behavioral pattern (hostility, rage, intense ambition, general sense of urgency) $[36,37]$. Furthermore, recently type D personality, characterized with tendency to experience increased negative emotions across time and situations, was shown to be an independent risk factor for cardiovascular events in patients with known heart disease $[38,39]$.

\section{Stress Response Mechanisms}

Stress response is an adaptive mechanism in a short term, but if it continues for a longer term at a certain level, it becomes maladaptive. In terms of physiological responses, two major systems are activated: the sympathetic nervous system and the hypothalamicpituitary-adrenocortical (HPA) axis. While HPA axis stimulates adrenal cortex resulting in the excretion of glucocorticoids (cortisol and corticosteron), sympathetic system shows its effect with two parallel pathways. The aim of the acute response is to provide energy mobilization, which is adaptive in nature, in order to form a behavioral response against an internal or external stimulus. This response, on the contrary, is maladaptive if it continues at a certain level for a long term. Most common example of this condition is physiopathological events resulting from the hippocampal differences stimulated by long term increased-level of the glucocorticoids [40-42].

\section{HPA axis}

It has been known that levels of adrenocorticotropic hormone $(\mathrm{ACTH})$ and glucocorticoids increase with chronic stress. Inhibition of feedback mechanism with increased cortisol levels and depending on this, hyper activation of HPA system were shown both in animal and human studies [43-45]. These increases are prominent, especially in depressive patients $[46,47]$. When considered from the perspective of cardiovascular system, high glucocorticoid levels play important role especially in hypertension, insulin resistance, hyperglycemia and weight gain $[48,49]$. Besides, if we remember that glucocorticoids basically play active role in inflammation, the connection between high glucocorticoid levels and atherosclerosis can be established easily. As a matter of fact, in cases like Cushing's syndrome in which glucocorticoid levels are high, atherosclerosis is prominently observed [50]. Again HPA axis plays a role in the alterations of the organ physiology and metabolic parameters, which are affected from emotional changes. According to the study conducted by Selye, basic physiological changes are decrease in the body weight and body fat amount, atrophy in thymus and enlargement in adrenal glands [51]. These results were also supported with animal studies [52]. According to the study of Bartolomucci et al. changes observed in the body weight with stress were associated with social statue. That means, loss of weight was observed in dominant animals in the group with chronic stress, on contrary weight gain was observed in recessive ones. According to the researchers, weight loss in the dominant animals depended on decreasing food intake because of HPA axis and locomotor system activation, on the other hand, weight gain in recessive animals was explained with increased food consumption resulting from depressive behaviors [44]. Likewise, in two separate studies, similar results were shown and the role of 5-HT1 receptors in depressive symptoms and food intake was proven $[53,54]$.

\section{Sympathetic nervous system}

Hyperactivation of sympathetic nerve system with chronic stress and emotional disorders has already been known [55]. Similarly, the association between sympathetic nerve system activation and psychological factors in patients with cardiovascular disease was shown in many studies [56]. 
In the cardiovascular system the sympathetic tone is regulated both in the short and long term, mainly by two neural mechanisms [57]: 1) the feedback mechanisms, 2) the central control mechanisms. While feedback mechanism is responsible for short-term activation, central control mechanism is involved in the long-term activation of sympathetic nerve system. Most important feedback mechanism in cardiovascular system is baroreflex of short-term arterial pressure regulation. Though central control mechanisms of the sympathetic tone are more complex and are associated with behavioral strategies, (such as those involved in exercise or in response to emotional stress), emotional stress can exert influence on the sympathetic activity both in short and long term [58].

It is well known that activation of sympathetic nervous system induces increase in heart rate, blood vessel tone, myocardial oxygen consumption, activation of the renin-angiotensin system (RAS) and increase in oxidative stress (via Ang II/NADPH pathway) [46,59].

\section{Other mechanisms}

In addition to the HPA axis and sympathetic nerve system, it has been reported that various systems are activated as stress response. One of them is the activation of immune system. Most important changes are decrease in lymphocyte proliferation and reduction of cytokines and antibody production [60-62]. According to the previous studies, especially corticosterone, and other stress hormones, such as endorphins and catecholamine could be responsible from this alleviation $[63,64]$. Other important components of immune system are cytokines, which are basic proteins in immune system providing connection. A number of studies have showed changes in the amount of these proteins in brain caused by chronic stress. In these studies, only with chronic stress application without any inflammatory stimulus, decreased hippocampal IL-1 $\beta$ and striatal TNF- $\alpha$ levels were found in animals. This decrease in cytokines levels was negatively associated with the increase in glucocorticoid levels. These results showed that brain cytokine levels have very important roles in chronic stress response but their roles cannot be explained completely [65]. Furthermore, stress induced activation of humoral factors including neurotropins (NTs) and the corticotrophin releasing factor (CRF), which are members of family of neuropeptides, play role in the stress response. NTs are responsible for the survival, growth, maintenance and death of central and peripheral neurons. Increased secretion of NTs from the hypothalamus, pituitary gland and central and peripheral nerves under physiological stress was shown [66]. Brain derived neurotropic factor (BDNF), a member of NT family, is a well-recognized protective mechanism against stress stimulus in the brain. BDNF protects striatal neurons from cell death by acting as an antioxidant [67]. On the contrary, recent studies showed that the expression of BDNF in the aortic wall and coronary arteries was associated with enhancement of NADPH oxidase activity and superoxide production [68]. Therefore, further studies are needed to clarify this controversy. CRF controls the HPA axis under both basal and stress conditions and play a role in stress related pathophysiology and behavior. By combining different receptors (CRFR1 and CRFR2), CRF plays a role both in initiation and termination of stress response [69]. Despite the presence of CRFR2 in vascular endothelial cells, its role in stress response remains unknown at present.

When all changes are considered from the perspective of cardiovascular event, the figure below comes into the picture (Figure $1)$.

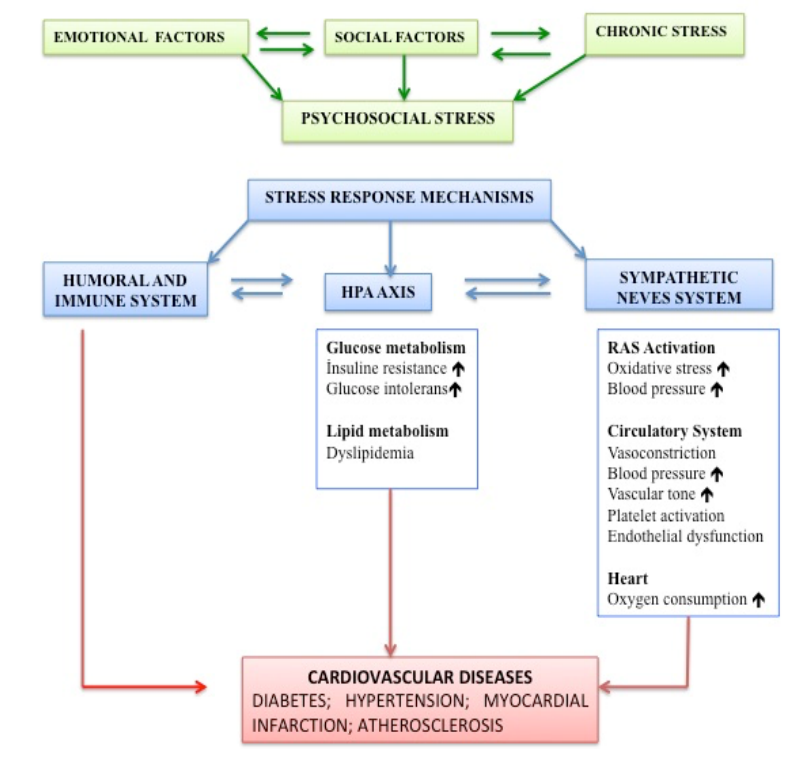

Figure 1 Psychosocial stress as risk factors for cardiovascular diseases.

\section{Conclusion}

In addition to being a risk factor for CVD, chronic stress plays a substantial role in the prognosis of CVD. It should also be kept in mind that emotional disorders, especially depression, could mask the cardiac symptoms. Moreover, it should not be forgotten that especially patient compliance, the key for the success of medical treatment, can change with emotional factors. When considered from this respect, either in the diagnosis of the cardiovascular events or in the decision of treatment strategy, good search of psychosocial condition and addition of rehabilitation and supportive programs to the treatment regimen have been reported to be important factors affecting the quality and efficacy of the therapy.

In the light of the evidence, it is obvious that greater attention should be given to the assessment of the impact of psychosocial factors in daily cardiology practices. What is more, in patients with known heart disease new clinical protocols including the assessment of emotional and cognitive factors for cardiovascular risk estimates should be developed, and additionally these factors should be considered as part of secondary prevention approaches.

\section{References}

1. Selye H, Fortier C (1949) Adaptive reactions to stress. Res Publ Assoc Res Nerv Ment Dis 29: 3-18.

2. Selye H, Fortier C (1950) Adaptive reaction to stress. Psychosom Med 12 149-157.

3. Yusuf S, Reddy S, Ounpuu S, Anand S (2001) Global burden of cardiovascular diseases: part I: general considerations, the epidemiologic transition, risk factors, and impact of urbanization. Circulation 104: 2746-2753.

4. Yusuf S, Reddy S, Ounpuu S, Anand S (2000) Global burden of cardiovascular diseases: part II: variations in cardiovascular disease by specific ethnic groups and geographic regions and prevention strategies. Circulation 104: 2855-2864.

5. Greenland P, Knoll MD, Stamler J, Neaton JD, Dyer AR, et al. (2003) Majo risk factors as antecedents of fatal and nonfatal coronary heart disease events. JAMA 290: 891-897.

6. Magnus $\mathrm{P}$, Beaglehole $\mathrm{R}$ (2001) The real contribution of the major risk factors to the coronary epidemics: time to end the "only-50\%" myth. Arch Intern Med 161: $2657-2660$ 
7. Inoue N1 (2014) Stress and atherosclerotic cardiovascular disease. J Atheroscler Thromb 21: 391-401.

8. Clouse RE, Lustman PJ, Freedland KE, Griffith LS, McGill JB, et al. (2003) Depression and coronary heart disease in women with diabetes. Psychosom Med 65: 376-383.

9. Rozanski A, Blumenthal JA, Kaplan J (1999) Impact of psychological factors on the pathogenesis of cardiovascular disease and implications for therapy. Circulation 99: 2192-2217.

10. Case RB, Moss AJ, Case N, McDermott M, Eberly S (1992) Living alone after myocardial infarction. Impact on prognosis. JAMA 267: 515-519.

11. Williams RB, Barefoot JC, Califf RM, Haney TL, Saunders WB, et al. (1992) Prognostic importance of social and economic resources among medically treated patients with angiographically documented coronary artery disease. JAMA 267: 520-524.

12. Ruberman W, Weinblatt E, Goldberg JD, Chaudhary BS (1984) Psychosocial influences on mortality after myocardial infarction. N Engl J Med 311: 552-559.

13. Marmot MG, Bosma H, Hemingway H, Brunner E, Stansfeld S (1997) Contribution of job control and other risk factors to social variations in coronary heart disease incidence. Lancet 350: 235-239.

14. Johnson JV, Hall EM, Theorell T (1989) Combined effects of job strain and social isolation on cardiovascular disease morbidity and mortality in a random sample of the Swedish male working population. Scand J Work Environ Health 15: $271-279$

15. Kivimäki M, Leino-Arjas $P$, Luukkonen R, Riihimäki $H$, Vahtera J, et al. (2002) Work stress and risk of cardiovascular mortality: prospective cohort study of industrial employees. BMJ 325: 857.

16. Johnson JV, Stewart W, Hall EM, Fredlund P, Theorell T (1996) Long-term psychosocial work environment and cardiovascular mortality among Swedish men. Am J Public Health 86: 324-331.

17. Matthews KA, Gump BB (2002) Chronic work stress and marital dissolution increase risk of posttrial mortality in men from the Multiple Risk Factor Intervention Trial. Arch Intern Med 162: 309-315.

18. Orth-Gomér K, Wamala SP, Horsten M, Schenck-Gustafsson K, Schneiderman $\mathrm{N}$, et al. (2000) Marital stress worsens prognosis in women with coronary heart disease: The Stockholm Female Coronary Risk Study. JAMA 284: 3008-3014.

19. Yusuf S, Hawken S, Ounpuu S, Dans T, Avezum A, et al. (2004) Effect of potentially modifiable risk factors associated with myocardial infarction in 52 countries (the INTERHEART study): case-control study. Lancet 364: 937-952.

20. Pratt LA, Ford DE, Crum RM, Armenian HK, Gallo JJ, et al. (1996) Depression, psychotropic medication, and risk of myocardial infarction. Prospective data from the Baltimore ECA follow-up. Circulation 94: 3123-3129.

21. Frasure-Smith N, Lespérance F, Talajic M (1995) Depression and 18-month prognosis after myocardial infarction. Circulation 91: 999-1005.

22. Kim CK, McGorray SP, Bartholomew BA, Marsh M, Dicken T, et al. (2005) Depressive symptoms and heart rate variability in postmenopausal women. Arch Intern Med 165: 1239-1244.

23. Rumsfeld JS, Havranek E, Masoudi FA, Peterson ED, Jones P, et al. (2003) Depressive symptoms are the strongest predictors of short-term declines in health status in patients with heart failure. J Am Coll Cardiol 42: 1811-1817.

24. Lespérance F, Frasure-Smith N, Talajic M, Bourassa MG (2002) Five-year risk of cardiac mortality in relation to initial severity and one-year changes in depression symptoms after myocardial infarction. Circulation 105: 1049-1053.

25. Strik JJ, Denollet J, Lousberg R, Honig A (2003) Comparing symptoms of depression and anxiety as predictors of cardiac events and increased health care consumption after myocardial infarction. J Am Coll Cardiol 42: 1801-1807.

26. Székely A, Balog P, Benkö E, Breuer T, Székely J, et al. (2007) Anxiety predicts mortality and morbidity after coronary artery and valve surgery--a 4-year followup study. Psychosom Med 69: 625-631.

27. Tully PJ, Baker RA, Knight $\mathrm{JL}$ (2008) Anxiety and depression as risk factors for mortality after coronary artery bypass surgery. J Psychosom Res 64: 285-290.

28. Lane D, Carroll D, Ring C, Beevers DG, Lip GY (2001) Mortality and quality of life 12 months after myocardial infarction: effects of depression and anxiety. Psychosom Med 63: 221-230.
29. van Melle JP, de Jonge P, Spijkerman TA, Tijssen JG, Ormel J, et al. (2004) Prognostic association of depression following myocardial infarction with mortality and cardiovascular events: a meta-analysis. Psychosom Med 66: 814-822.

30. Barsky AJ (2005) Psyciatric and behaviorla aspects of cardiovascular disease in Braunwald's Heart Disease A textbook of Cardiovascular Medicine (Zipes D.P, Libby P, Bonow O. R, Braunwald E eds). 7th edition, Elsevier Saunders, Philadelphia, Pennsylvania, pp: 2129-2144.

31. Rugulies R1 (2002) Depression as a predictor for coronary heart disease. a review and meta-analysis. Am J Prev Med 23: 51-61.

32. Glassman AH, O'Connor CM, Califf RM, Swedberg K, Schwartz P, et al. (2002) Sertraline treatment of major depression in patients with acute $\mathrm{MI}$ or unstable angina. JAMA 288: 701-709.

33. Berkman LF, Blumenthal J, Burg M, Carney RM, Catellier D, et al. (2003) Effects of treating depression and low perceived social support on clinical events after myocardial infarction: the Enhancing Recovery in Coronary Heart Disease Patients (ENRICHD) Randomized Trial. JAMA 289: 3106-3116.

34. Kawachi I, Sparrow D, Vokonas PS, Weiss ST (1994) Symptoms of anxiety and risk of coronary heart disease. The Normative Aging Study. Circulation 90: 2225-2229.

35. Kawachi I, Colditz GA, Ascherio A, Rimm EB, Giovannucci E, et al. (1994) Prospective study of phobic anxiety and risk of coronary heart disease in men. Circulation 89: 1992-1997.

36. Myrtek M1 (2001) Meta-analyses of prospective studies on coronary heart disease, type A personality, and hostility. Int J Cardiol 79: 245-251.

37. Chida Y, Steptoe A (2009) The association of anger and hostility with future coronary heart disease: a meta-analytic review of prospective evidence. J Am Coll Cardiol 53: 936-946.

38. Denollet J, Vaes J, Brutsaert DL (2000) Inadequate response to treatment in coronary heart disease : adverse effects of type $\mathrm{D}$ personality and younger age on 5-year prognosis and quality of life. Circulation 102: 630-635.

39. Denollet J, Brutsaert DL (1998) Personality, disease severity, and the risk of long-term cardiac events in patients with a decreased ejection fraction after myocardial infarction. Circulation 97: 167-173.

40. McEwen BS1 (1998) Protective and damaging effects of stress mediators. N Engl J Med 338: 171-179.

41. McEwen BS1 (2000) The neurobiology of stress: from serendipity to clinical relevance. Brain Res 886: 172-189.

42. Fuchs E, Flügge G (2002) Social stress in tree shrews: effects on physiology brain function, and behavior of subordinate individuals. Pharmacol Biochem Behav 73: 247-258.

43. Bartolomucci A, Pederzani T, Sacerdote $P$, Panerai AE, Parmigiani $S$, et al. (2004) Behavioral and physiological characterization of male mice under chronic psychosocial stress. Psychoneuroendocrinology 29: 899-910.

44. Bartolomucci A, Palanza P, Parmigiani S, Pederzani T, Merlot E, et al. (2003) Chronic psychosocial stress down-regulates central cytokines mRNA. Brain Res Bull 62: 173-178.

45. Jacobson L, Sapolsky R (1991) The role of the hippocampus in feedback regulation of the hypothalamic-pituitary-adrenocortical axis. Endocr Rev 12 118-134.

46. Pariante CM, Miller AH (2001) Glucocorticoid receptors in major depression relevance to pathophysiology and treatment. Biol Psychiatry 49: 391-404.

47. Holsboer F (2000) The corticosteroid receptor hypothesis of depression. Neuropsychopharmacology 23: 477-501.

48. Friedman TC, Mastorakos G, Newman TD, Mullen NM, Horton EG, et al. (1996) Carbohydrate and lipid metabolism in endogenous hypercortisolism: shared features with metabolic syndrome $X$ and NIDDM. Endocr J 43: 645-655.

49. Yanovski JA, Cutler GB Jr (1994) Glucocorticoid action and the clinical features of Cushing's syndrome. Endocrinol Metab Clin North Am 23: 487-509.

50. Colao A, Pivonello R, Spiezia S, Faggiano A, Ferone D, et al. (1999) Persistence of increased cardiovascular risk in patients with Cushing's disease after five years of successful cure. J Clin Endocrinol Metab 84: 2664-2672. 
Citation: Mercanoglu G, Macit C, Mercanoglu F (2015) Stress as a Risk Factor for Cardiovascular Events. Cardiol Pharmacol 4: 140. doi:10.4172/23296607.1000140

51. Veissier I, Boissy A (2007) Stress and welfare: two complementary concepts that are intrinsically related to the animal's point of view. Physiol Behav 92 429-433.

52. Sgoifo A, Koolhaas J, De Boer S, Musso E, Stilli D, et al. (1999) Social stress, autonomic neural activation, and cardiac activity in rats. Neurosci Biobehav Rev 23: 915-923

53. Bouwknecht JA, van der Gugten J, Hijzen TH, Maes RA, Hen R, et al. (2001) Male and female 5-HT(1B) receptor knockout mice have higher body weights than wildtypes. Physiol Behav 74: 507-516.

54. Holmes A, Yang RJ, Murphy DL, Crawley JN (2002) Evaluation of antidepressant-related behavioral responses in mice lacking the serotonin transporter. Neuropsychopharmacology 27: 914-923.

55. Mason JW (1968) A review of psychoendocrine research on the sympatheticadrenal medullary system. Psychosom Med 30: Suppl:631-653.

56. Lambert E, Dawood T, Straznicky N, Sari C, Schlaich M, et al. (2010) Association between the sympathetic firing pattern and anxiety level in patients with the metabolic syndrome and elevated blood pressure. J Hypertens 28: 543-550

57. Dampney RA, Coleman MJ, Fontes MA, Hirooka Y, Horiuchi J, et al. (2002) Central mechanisms underlying short- and long-term regulation of the cardiovascular system. Clin Exp Pharmacol Physiol 29: 261-268.

58. Fontes MA, Xavier CH, Marins FR, Limborço-Filho M, Vaz GC, et al. (2014) Emotional stress and sympathetic activity: contribution of dorsomedial hypothalamus to cardiac arrhythmias. Brain Res 1554: 49-58.

59. Costoli T, Bartolomucci A, Graiani G, Stilli D, Laviola G, et al. (2004) Effects of chronic psychosocial stress on cardiac autonomic responsiveness and myocardial structure in mice. Am J Physiol Heart Circ Physiol 286: H21332140.

60. Stefanski V1 (2000) Social stress in laboratory rats: hormonal responses and immune cell distribution. Psychoneuroendocrinology 25: 389-406.
61. Fleshner M, Laudenslager ML, Simons L, Maier SF (1989) Reduced serum antibodies associated with social defeat in rats. Physiol Behav 45: 1183-1187.

62. Raab A, Dantzer R, Michaud B, Mormede P, Taghzouti K, et al. (1986) Behavioural, physiological and immunological consequences of social status and aggression in chronically coexisting resident-intruder dyads of male rats. Physiol Behav 36: 223-228.

63. Sacerdote P, Manfredi B, Gaspani L, Panerai AE (2000) The opioid antagonist naloxone induces a shift from type 2 to type 1 cytokine pattern in BALB/cJ mice. Blood 95: 2031-2036.

64. Kruszewska B, Felten SY, Moynihan JA (1995) Alterations in cytokine and antibody production following chemical sympathectomy in two strains of mice. J Immunol 155: 4613-4620.

65. Plata-Salaman CR, Llyin SE, Turrin NP, Gayle D, Flynn MC et al. (2000) Neither acute nor chronic exposure to a naturalistic (predator) stressor influence the interleukine-1b system, tumor necrosis factor- $a$, transforming growth factor-b, and neuropeptide mRNAs in specific brain regions. Brain Res Bull 51:187-193.

66. Naert G, Ixart G, Maurice T, Tapia-Arancibia L, Givalois L (2011) Brainderived neurotrophic factor and hypothalamic- pituitary-adrenal axis adaptation processes in a depressive- like state induced by chronic restraint stress. Mol Cell Neurosci 46: 55-66.

67. Lee B, Cao R, Choi YS, Cho HY, Rhee AD, et al. (2009) The CREB/CRE transcriptional pathway: protection against oxidative stress-mediated neuronal cell death. J Neurochem 108: 1251-1265.

68. Karlovic D, Serretti A, Jevtovic S, Vrkic N, Šeric N et al. (2013) Diagnostic accuracy of serum brain derived neurotrophic factor concentration in antidepressant receive patients with first major depression episode. J Psychiatr Res 47: 162-167.

69. Joëls M, Baram TZ (2009) The neuro-symphony of stress. Nat Rev Neurosci 10: $459-466$. 